J. MED. MICROBIOL. - VOL. 16 (1983), 203-210

(C) 1983 The Pathological Society of Great Britain and Ireland

\title{
A NEW LIPOPOLYSACCHARIDE ANTIGEN IDENTIFIED IN ACINETOBACTER CALCOACETICUS: OCCURRENCE OF WIDESPREAD NATURAL ANTIBODY
}

\author{
H. BRade and C. Galanos \\ Max-Planck-Institut für Immunbiologie, Stübeweg 51, D-7800 Freiburg, Federal \\ Republic of Germany
}

SUMmarY. Serological investigation of the lipopolysaccharide (LPS) of Acinetobacter calcoaceticus revealed a new antigen to which antibody in high titre is present in the serum of many mammalian species. The passive haemolysis test showed that antibody, in titres ranging from 32-4096, was invariably present in the serum of mice, rats, guinea-pigs, and horses. Rabbits and human beings had lower and more variable titres $(<2-512)$. The antigen persisted after prolonged hydrolysis of the LPS in $1 \%$ acetic acid at $100^{\circ} \mathrm{C}$. Acinetobacter lipid $\mathrm{A}$, which resembled antigenically the lipid A of many gram-negative bacteria, could be distinguished from the new antigen by inhibition and absorption experiments. Antibody to the new antigen could be completely absorbed with acinetobacter lipid A but not with enterobacterial lipid A; moreover, the latter failed to react with the antibody in the passive haemolysis test. Immunisation of rabbits with lipid A-immunogenic acinetobacter cells gave rise to antibodies against the new antigen and to lipid-A antibodies. Absorption of the immune serum with acinetobacter lipid A removed antibody to both antigens, but absorption with enterobacterial lipid A removed only the lipid -A antibodies.

\section{INTRODUCTION}

Lipopolysaccharide (LPS) is a constituent of the outer membrane of gram-negative bacteria, conferring stability to the cell wall. LPSs influence pathogenicity by causing granulocytosis, fever, and haemodynamic changes leading to shock and death (Weinbaum, Kadis and Ajl, 1971). They are also potent antigens. All three regions of the LPS molecule-O polysaccharide, core, and lipid A - are immunogenic (Kauffmann, 1966; Lüderitz et al., 1966; Galanos, Lüderitz and Westphal, 1971). The O polysaccharide and its antibodies have been investigated intensively (Kauffmann, 1966; Lüderitz et al., 1966). O antibodies are specific for a given serotype. Core antigens, which are limited in number, are identical in many species. They have been defined chemically, but the biological relevance of their corresponding antibodies is uncertain (Lüderitz et al., 1966; Chedid et al., 1968; Ziegler et al., 1973; Braude et al., 
1977; McCabe et al., 1977). Lipid A usually consists of a phosphorylated glucosamine disaccharide substituted with ester- and amide-linked fatty acids; little is known about lipid-A antibodies in terms of biological properties (Galanos et al., 1977; Galanos, Lüderitz and Westphal, 1979), but they frequently cross-react with lipid A from bacteria belonging to heterologous gram-negative genera (Galanos et al., 1971).

In a preceding paper, we described the isolation and purification of the LPS of Acinetobacter calcoaceticus (Brade and Galanos, 1982). The physico-chemical properties and the analytical data revealed an R-like LPS structure resembling that of rough mutants of Enterobacteriaceae. In this study, we report a new antigen in the LPS and lipid A of $A$. calcoaceticus, against which many mammalian species, including man, have naturally occurring antibodies.

\section{MATERIALS AND METHODS}

Lipopolysaccharide and lipid A. Strain NCTC10305 of A. calcoaceticus was used. The preparation of pure LPS in the uniform triethylamine or sodium salt form and of free lipid A was carried out as described earlier (Galanos et al., 1979; Brade and Galanos, 1982). Enterobacterial lipid A from Salmonella minnesota strain R595 (Re) was also used.

Immune sera. Lipid-A antisera were obtained by immunising New Zealand White rabbits with acid-treated $\left(1 \%\right.$ acetic acid, $\left.100^{\circ} \mathrm{C}, 1 \mathrm{~h}\right) \mathrm{A}$. calcoaceticus strain NCTC10305 according to the procedure of Galanos et al. (1971). Animals received 50,100,200, and $400 \mu \mathrm{g}$ of lyophilysed bacteria intravenously on days $0,4,7$ and 11 , respectively, and were bled on day 16 . The serum collected was absorbed with sheep red-blood cells (SRBC) and stored at $-20^{\circ} \mathrm{C}$.

Normal sera. Sera from mice (strains NMRI, C3H/HeJ, C57BL/6, and NuNu), rats, guinea-pigs and rabbits were obtained from the animal stock of our Institute. Horse sera were kindly provided by Professor D. Hammer. Normal human sera were obtained from healthy blood donors, aged 20-65 years, of both sexes.

Serology. SRBC coated with alkali-treated LPS or lipid A, and guinea-pig complement, were used in the passive haemolysis and passive haemolysis inhibition tests, as described by Neter (1956) and Galanos et al. (1971). The release of free lipid A from LPS during hydrolysis was followed serologically by inhibition tests. Samples of $1 \mathrm{mg}$ of LPS were hydrolysed in sealed ampoules in $200 \mu \mathrm{l}$ of $1 \%$ acetic acid at $100^{\circ} \mathrm{C}$ for different times, cooled in iced water, and diluted with $800 \mu \mathrm{l}$ of distilled water; the $p \mathrm{H}$ was adjusted to 7.0 with triethylamine.

Absorption experiments. Undiluted antiserum $(500 \mu \mathrm{l})$ was absorbed at $0^{\circ} \mathrm{C}$ for $1 \mathrm{~h}$ with 100 $\mu \mathrm{l}$ of packed SRBC coated with either acinetobacter or salmonella alkali-treated lipid A, and centrifuged under refrigeration. Alternatively, antisera were fractionated on immunoabsorbent columns. Acinetobacter or salmonella lipid A which had been treated with hydrazine at $60^{\circ} \mathrm{C}$ for $2 \mathrm{~h}$ was coupled to AH-sepharose $4 \mathrm{~B}$ (Deutsche Pharmacia, Freiburg) by means of glutardialdehyde (Galanos, unpublished data). Absorption of antibodies was carried out at room temperature in phosphate-buffered saline (PBS) by recycling the serum with a peristaltic pump. The column was washed thoroughly with PBS and the absorbed antibodies were eluted with $0.1 \mathrm{M}$ glycine in $\mathrm{HCl}, p \mathrm{H} \mathrm{2.8}$, and collected in ice-cold PBS (10-fold ionic strength). The fraction which had not been absorbed by the column, and the eluted fraction, were concentrated to the original volume by vacuum dialysis and examined by the passive haemolysis test.

\section{RESULTS}

\section{Serological properties}

The antigenic similarity between acinetobacter and salmonella lipid A was investigated by the passive haemolysis and passive-haemolysis inhibition tests. The results are given in table $\mathrm{I}$. 
TABLE I

Reactivity of lipid A from Salmonella minnesota R595 (Re) and Acinetobacter calcoaceticus NCTC10305 with homologous and heterologous antiserum before and after absorption with homologous and heterologous lipid A-coated erythrocytes

\begin{tabular}{l|cc}
\hline & \multicolumn{2}{c}{$\begin{array}{c}\text { Passive haemolysis-test titres when } \\
\text { erythrocytes were coated with lipid A from }\end{array}$} \\
\cline { 2 - 3 } Antiserum & $\mathbf{S}$ minnesota & A. calcoaceticus \\
\hline Salmonella lipid A & $\mathbf{2 0 4 8}$ & 2048 \\
Before absorption & $<2$ & $<2$ \\
Absorbed with homologous lipid A & $<2$ & $<2$ \\
Absorbed with acinetobacter lipid A & 2048 & $\mathbf{2 5 6 0 0}$ \\
Acinetobacter lipid A & $<2$ & $\mathbf{2 0}$ \\
Before absorption & $<2$ & $\mathbf{2 5 6 0 0}$ \\
Absorbed with homologous lipid A & 2 & \\
Absorbed with salmonella lipid A & & \\
\hline
\end{tabular}

Salmonella lipid-A antiserum reacted strongly with SRBC coated with either salmonella or acinetobacter lipid A. As in previous studies, salmonella lipid-A antiserum showed no interaction with SRBC coated with acinetobacter LPS (data not shown). In inhibition tests with salmonella lipid-A antiserum (table II), the lysis of SR BC coated with either acinetobacter or salmonella lipid A was completely inhibited by both types of lipid A. Moreover, absorption of salmonella lipid-A antiserum with salmonella or acinetobacter lipid A abolished completely its activity against both antigens (table I). From these results it is concluded that the lipid-A antigen present in all members of the Enterobacteriaceae is also present in A. calcoaceticus.

The use of acinetobacter lipid-A antiserum led to unexpected results. In the passive haemolysis test (table I), the acinetobacter lipid-A antiserum reacted with SR BC coated with either acinetobacter or salmonella lipid A, with titres of 25600 and 2048 respectively. In the inhibition test (table II), acinetobacter lipid A inhibited the activity of the antiserum against both antigen preparations. Salmonella lipid A,

TABLE II

Inhibition of passive haemolysis by free lipid A from S. minnesota and A. calcoaceticus

\begin{tabular}{l|cc}
\hline & $\begin{array}{c}\text { Minimal inhibitory concentration }(\mu \mathrm{g}) \\
\text { of free lipid A from }\end{array}$ \\
\cline { 2 - 3 } Antigen-antibody* system & S. minnesota & A. calcoaceticus \\
\hline $\begin{array}{c}\text { Salmonella lipid A and anti- } \\
\text { salmonella lipid A }\end{array}$ & 0.016 & 0.032 \\
$\begin{array}{c}\text { Acinetobacter lipid A and anti- } \\
\text { salmonella lipid A }\end{array}$ & 0.016 & 0.016 \\
$\begin{array}{c}\text { Acinetobacter lipid A and anti- } \\
\text { acinetobacter lipid A }\end{array}$ & $>5.0$ & 0.004 \\
$\begin{array}{c}\text { Salmonella lipid A and anti- } \\
\text { acinetobacter lipid A }\end{array}$ & 0.016 & 0.016 \\
\hline
\end{tabular}

*Three haemolytic units of antiserum were used. 
however, inhibited activity against SRBC coated with salmonella but not acinetobacter lipid A. Absorption of the antiserum with acinetobacter lipid A abolished completely its activity against both acinetobacter and salmonella lipid A. Absorption with salmonella lipid A, however, abolished activity against salmonella but not acinetobacter lipid A (table I). Similar results were obtained with lipid A from other Enterobacteriaceae (Escherichia coli and Proteus spp.; data not shown). These results show that acinetobacter lipid A contains, in addition to the already established antigen of lipid A, a new antigen; the latter is, however, absent from the lipid A of S. minnesota strain $\mathrm{R} 595(\mathrm{Re})$. Immunisation of rabbits with acid-treated acinetobacter cells leads to the production of antibodies against both antigens.

TABLE III

Fractionation of acinetobacter lipid-A antiserum with acinetobacter and salmonella lipid-A immunosorbent

\begin{tabular}{|c|c|c|}
\hline \multirow[b]{2}{*}{ Acinetobacter lipid-A antiserum } & \multicolumn{2}{|c|}{$\begin{array}{l}\text { Passive haemolysis-test titres when } \\
\text { erythrocytes were coated with lipid A from }\end{array}$} \\
\hline & S. minnesota & A. calcoaceticus \\
\hline $\begin{array}{l}\text { before absorption } \\
\text { after acinetobacter lipid- } A \\
\text { immunoabsorption } \\
\text { Unabsorbed fraction } \\
\text { Eluted fraction } \\
\text { after salmonella lipid-A } \\
\text { immunoabsorption } \\
\text { Unabsorbed fraction } \\
\text { Eluted fraction }\end{array}$ & $\begin{array}{r}<2 \\
1024\end{array}$ & $\begin{array}{r}<20 \\
12800\end{array}$ \\
\hline
\end{tabular}

The presence of two different antigens in acinetobacter lipid A, and of their corresponding antibodies in acinetobacter lipid-A antiserum, was also demonstrated by immunoabsorption experiments. Antiserum to acinetobacter lipid A was fractionated on immunoabsorbent columns to which either acinetobacter or salmonella lipid A had been coupled. The fraction that did not bind to the immunoabsorbent, and the eluted antibodies were examined separately (table III). Both antibodies were absorbed by the acinetobacter lipid-A immunosorbent, and recovered almost completely by elution. The salmonella lipid-A immunosorbent bound those lipid-A antibodies that, after elution, reacted with SRBC coated with lipid A from both Acinetobacter and Salmonella. Antibody to the new antigen was not bound by the immunosorbent, and reacted only with SRBC coated with acinetobacter lipid A.

\section{Rate of appearance of the two lipid-A antigens during acid hydrolysis of acinetobacter LPS}

This was studied by measuring, by the passive haemolysis method, the inhibitory activity of hydrolysed LPS for the following antigen-antibody systems: salmonella lipid $\mathrm{A}$ with homologous antiserum, and acinetobacter lipid $\mathrm{A}$ with homologous antiserum. The figure shows that the intact LPS did not inhibit the salmonella system. This confirms the known masked character of the lipid-A antigen. After $3 \mathrm{~min}$, a considerable amount of free lipid A was detected (inhibition value $250 \mathrm{ng}$ ). The 


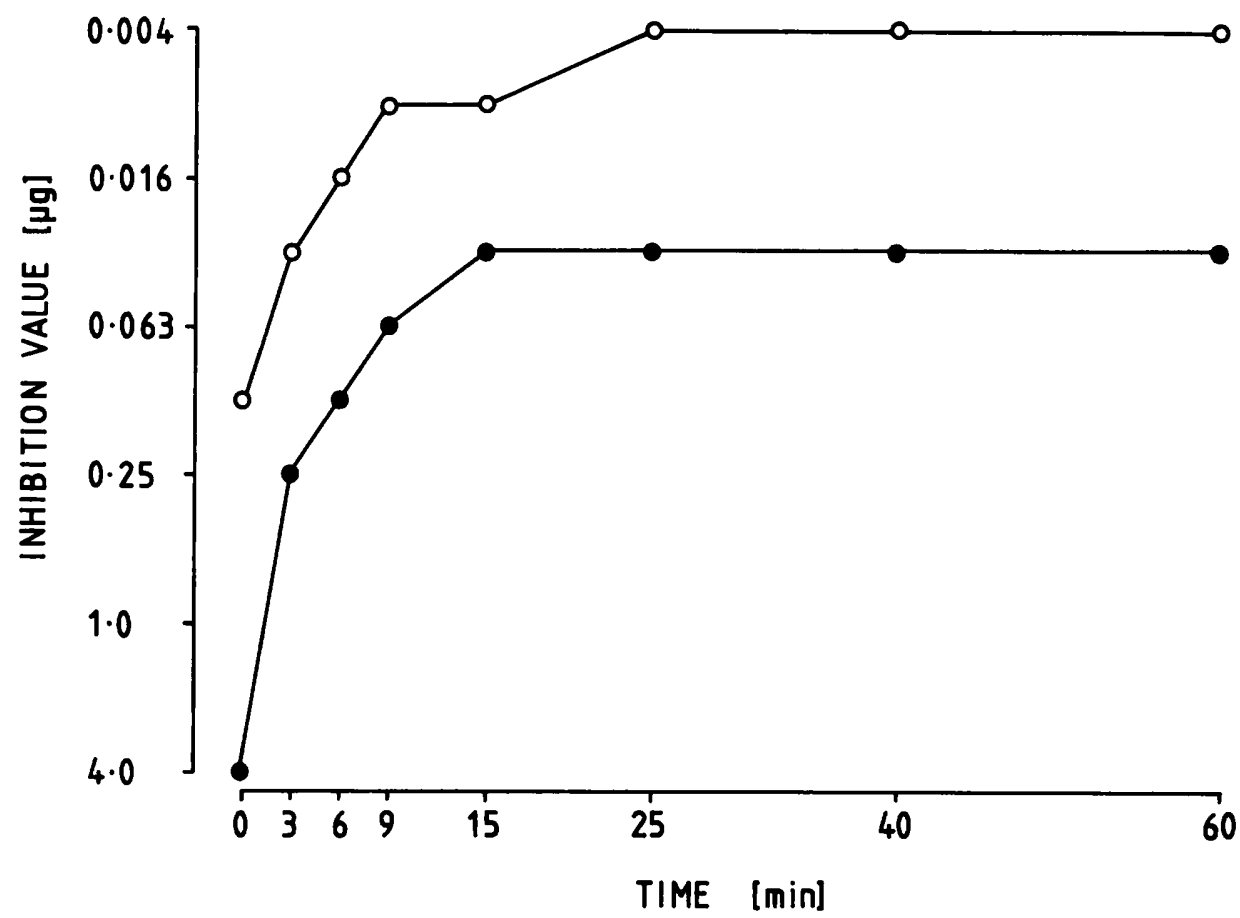

FIGURE-Rate of release of free lipid A from lipopolysaccharide of Acinetobacter calcoaceticus (NCTC10305) by hydrolysis in $1 \%$ acetic acid at $100^{\circ} \mathrm{C}$. Free lipid A was estimated by its inhibition of the passive-haemolysis systems (1) salmonella lipid A and homologous antiserum (0), and (2) acinetobacter lipid A and homologous antiserum (O). Inhibition values are given in $\mu \mathrm{g}$ of hydrolysed lipopolysaccharide inhibiting 3 hemolytic units of antiserum.

maximal inhibition value $(32 \mathrm{ng})$ was reached after $15 \mathrm{~min}$. The release of 3-deoxy-D-manno-octulosonic acid ( $\mathrm{dOclA}$ ) paralleled the release of free lipid A (data not shown). In contrast, in the acinetobacter system the intact LPS showed a significant inhibition value (125 $\mathrm{ng}$ ). The maximal value $(4 \mathrm{ng})$ was obtained after hydrolysis for $25 \mathrm{~min}$. These results show that, unlike the established lipid -A antigen, the new antigen is already unmasked to some extent in intact LPS. Acid hydrolysis leads to its complete unmasking.

\section{Occurrence of natural antibody to the new lipid-A antigen of $A$. calcoaceticus}

The presence of antibody to acinetobacter lipid $A$ in the serum of different animal species was studied by the passive haemolysis test, in which SRBC were coated with acinetobacter lipid A. As in all the experiments described above, fresh guinea-pig serum absorbed with acinetobacter lipid $\mathrm{A}$ was used as a source of complement, because, as will be shown below, normal guinea-pig serum is rich in antibody to the new lipid-A antigen.

Table IV shows the results. The highest antibody concentrations occurred in mice (including NuNu mice and the LPS non-responder strain C3H/HeJ; see Sultzer, 1972) and rats, in which titres of 1024-4096 and 512-1024, respectively, were found. Antibody was present in all individuals tested (60 mice and 30 rats), without significant 
TABLE IV

Natural antibody to the new lipid-A antigen from A. calcoaceticus in different mammalian species

\begin{tabular}{lc}
\hline \multicolumn{1}{c}{ Species $(\mathrm{n}=)$} & Titres (passive haemolysis test) \\
\hline Mouse, adult*(60) & $1024-4096$ \\
newborn $+(10)$ & $32-64$ \\
Rat (30) & $512-1024$ \\
Guinea-pig (40) & $64-256$ \\
Horse (8) & $512-2048$ \\
Rabbit (30) & $<2-256$ \\
Man (30) & $<2-512$ \\
\hline
\end{tabular}

* Strains C57BL/6, NMRI, C3H/HeJ, NuNu.

† Strain C57BL/6.

strain-dependent variation. In newborn mice (C57BL/6), the titres were lower (32-64) than in adults. Antibody was found in each of 40 guinea-pigs with titres of 64-256. Eight horse sera had titres of 512-2048. Antibodies also occurred in man and rabbits, but in these species the titres varied greatly $(<2-512)$.

\section{Discussion}

Serological examination of the lipid A of $A$. calcoaceticus revealed an antigen present also in the lipid A of members of the Enterobacteriaceae; and in addition a new antigen, to which natural antibodies are present in the serum of different mammalian species, including man.

The antigen of the well established type was demonstrated by the passive haemolysis test, in which antiserum against $S$. minnesota lipid A reacted equally with salmonella and acinetobacter lipid A absorbed to SRBC. All haemolytic activity was completely inhibited or absorbed by both acinetobacter and salmonella lipid A. The antigenic similarity between the lipid A of $A$. calcoaceticus and the members of the Enterobacteriaceae accords with chemical observations. In an earlier study, acinetobacter lipid A was shown to contain glucosamine 2 mol, amide-linked 2-hydroxylauric acid $2 \mathrm{~mol}$, and esterbound fatty acids (lauric-, 2- and 3-hydroxylauric acid) $4 \mathrm{~mol}$; phosphate and glucose were also present (Brade and Galanos, 1982).

For salmonella lipid $A$, the minimal structure that still retained full antigenic activity was shown to be $\beta$-1,6-linked glucosamine disaccharide carrying at least one amide-linked 3-hydroxymyristic acid (Galanos et al., 1977). Although a glucosamine disaccharide has not been detected in acinetobacter lipid $\mathrm{A}$, the presence of glucosamine and amide-linked 3-hydroxy fatty acids fulfils the compositional requirements for lipid-A antigenicity. As in the Enterobacteriaceae, this antigen is normally present in a masked form. In respect of the release of lipid A antigen and 3-deoxy-D-manno-octulosonic acid from acinetobacter LPS by hydrolysis, A. calcoaceticus resembles members of the Enterobacteriaceae.

The presence of a new antigen, of a hitherto unrecognised type, in the lipid A of $A$. calcoaceticus became apparent when antiserum to acinetobacter lipid $\mathrm{A}$ was examined in the passive haemolysis test with acinetobacter and salmonella lipid A adsorbed to $\mathrm{SRBC}$. In the acinetobacter system the titre of the antiserum was higher (25600) than in the salmonella system (2048). Activity against salmonella lipid A was inhibited or 
absorbed by both antigen preparations, but that to acinetobacter lipid A only with the acinetobacter preparation. It should be noted that, because the antiserum's activity against salmonella lipid $\mathrm{A}$ was lower than that against the new antigen, at the antiserum dilution used in the inhibition test ( 3 haemolytic units) the salmonella lipid-A antibody was diluted out and played no rôle. The same was true for the absorption test, in which absorption with salmonella lipid A did not alter the overall activity of the serum against acinetobacter lipid $A$. It is interesting that, unlike the "classical" lipid-A antigen, which is expressed only in free lipid A after cleavage of the polysaccharide, the new antigen was already partly unmasked in intact acinetobacter LPS; it increased after removal of $\mathrm{dOcl} A$ by acid hydrolysis. In addition, the kinetics of the unmasking of each antigen during acid hydrolysis of acinetobacter LPS were distinctly different.

It is not yet known which structural component of acinetobacter lipid A accounts for the new antigen. As shown earlier, one main compositional difference between the salmonella and acinetobacter lipid $\mathrm{A}$ is the presence of glucose in the latter (Brade and Galanos, 1982). Although this sugar might appear an obvious candidate, it seems unlikely because we have recently found the new antigen under certain conditions in glucose-less LPS and LPS derivatives of gram-negative bacteria (including S-form bacteria) outside the family Neisseriaceae to which the genus Acinetobacter belongs (unpublished data).

An interesting biological finding of the present study is the ubiquitous presence of naturally occurring antibodies against the new antigen in the serum of man and all animal species investigated so far. Also interesting are the high concentrations of antibody in some species, particularly mice (including $\mathrm{C} 3 \mathrm{H} / \mathrm{HeJ}$ and $\mathrm{NuNu}$ mice), in which the titres ranged from 1024 to 4096; these may have been a reflection of the high number of plaque-forming cells found in the spleen (data not shown). Such titres are unusually high for natural antibodies (Galanos, 1972). Normal mouse serum does not contain classical lipid-A antibodies (Galanos et al., 1977). Thus, normal mouse serum constitutes a readily available and rich source of antibody to the new antigen, and is at the same time free of antibodies to the "classical" lipid-A antigen.

Current unpublished studies suggest that the new antigen is also present in the LPS of many members of the Enterobacteriaceae and of other families of gram-negative bacteria.

We are indebted to Dr O. Lüderitz for useful suggestions and to H. Wintersinger and M.-L. Gundelach for expert technical assistance. H. B. is a recipient of a grant from the Deutsche Forschungsgemeinschaft $(\mathrm{Br} 731 / 2)$.

\section{REFERENCES}

Brade, H. and Galanos, C. 1982. Isolation, purification and chemical analysis of the lipopolysaccharide and lipid A of Acinetobacter calcoaceticus NCTC 10305. European Journal of Biochemistry, 122, 233-237.

Braude, A. I., Ziegler, E. J., Douglas, H. and McCutchan, J. A. 1977. Antibody to cell wall glycolipid of gram-negative bacteria: induction of immunity to bacteremia and endotoxemia. Journal of Infectious Diseases, 136 Supplement, 167-173.

Chedid, L., Parant, M., Parant, F. AND Boyer, F. 1968. A proposed mechanism for natural immunity to enterobacterial pathogens. Journal of Immunology, 100, 292-301.

GALANOS, C. 1972. Anticomplementary activity of lipopolysaccharides and the role of natural antibodies. In European complement workshop, biochemistry and biology of the third 
component of complement, edited by K. W. Pondman and K. O. Rother. Central Laboratory of the Netherland Red Cross, Blood Transfusion Service, Amsterdam. pp 45-50.

Galanos, C., Freudenberg, M., Hase, S., Jay, F. and Ruschmann, E. 1977. Biological activities and immunological properties of lipid A. In Microbiology 1977, edited by D. Schlessinger. American Society for Microbiology, Washington, DC. pp 269-276.

Galanos, C., LÜDERITZ, O. AND WestPhal, O. 1971. Preparation and properties of antisera against the lipid-A component of bacterial lipopolysaccharides. European Journal of Biochemistry, 24, 116-122.

Galanos, C., LÜDeritz, O. AND Westrhal, O. 1979. Preparation and properties of a standardized lipopolysaccharide from Salmonella abortus equi (Novo-Pyrexal). Zentralblatt für Bakteriologie, Parasitenkunde, Infektionskrankheiten und Hygiene, I. Abt. Orig. A., 243, 226-244.

KaUfFMANN, F. 1966. The bacteriology of Enterobacteriaceae, Munksgaard, Copenhagen.

Lüderitz, O., Galanos, C., Risse, H. J., RuschmanN, E. Schlecht, S., Schmidt, G., Schulte-Holthausen, H., Wheat, R., Westphal, O. and Schlosshardt, J. 1966. Structural relationships of Salmonella $\mathrm{O}$ and $\mathrm{R}$ antigens. Annals of the New York Academy of Sciences, 133, 349-374.

MCCabe, W. R., Bruins, S. C., Craven, D. E. AND Johns, M. 1977. Cross-reactive antigens: Their potential for immunization-induced immunity to gram-negative bacteria. Journal of Infectious Diseases, 136 Supplement, 161-166.

NETER, E. 1956. Bacterial hemagglutination and hemolysis. Bacteriological Reviews, 20, $166-188$.

SULTZER, B. M. 1972. Genetic control of host responses to endotoxin. Infection and Immunity, 5, 107-113.

Weinbaum, G., Kadis, S. And AJ, S. J. (editors) 1971. Microbial toxins, Vol. 4 and 5. Academic Press, New York.

Ziegler, E. J., Douglas, H., Sherman, J. E., Davis, C. E. ANd Braude, A. I. 1973. Treatment of $E$. coli and Klebsiella bacteremia in agranulocytic animals with antiserum to a UDP-Gal epimerase-deficient mutant. Journal of Immunology, 111, 433-438. 